\title{
Prognostic value of magnetic resonance imaging findings in patients with sciatica
}

\author{
${ }^{*}$ Abdelilah el Barzouhi, MD, PhD, ${ }^{1}$ Annemieke J. H. Verwoerd, MD, PhD, ${ }^{2}$ Wilco C. Peul, MD, PhD, ${ }^{1,3}$ \\ Arianne P. Verhagen, $\mathrm{PhD},{ }^{2}$ Geert J. Lycklama à Nijeholt, MD, PhD, ${ }^{4}$ Bas F. Van der Kallen, MD, ${ }^{4}$ \\ Bart W. Koes, PhD, ${ }^{2}$ and Carmen L. A. M. Vleggeert-Lankamp, MD, PhD, ${ }^{1}$ for the \\ Leiden-The Hague Spine Intervention Prognostic Study Group
}

\begin{abstract}
1Department of Neurosurgery, Leiden University Medical Center, Leiden; ${ }^{2}$ Department of General Practice, Erasmus MC University Medical Center, Rotterdam; and Departments of ${ }^{3}$ Neurosurgery and ${ }^{4}$ Radiology, Medical Center Haaglanden, The Hague, The Netherlands
\end{abstract}

\begin{abstract}
OBJECTIVE This study aimed to determine the prognostic value of MRI variables to predict outcome in patients with herniated disc-related sciatica, and whether MRI could facilitate the decision making between early surgery and prolonged conservative care in these patients.
\end{abstract}

METHODS A prospective observational evaluation of patients enrolled in a randomized trial with 1-year follow-up was completed. A total of 283 patients with sciatica who had a radiologically confirmed disc herniation were randomized either to surgery or to prolonged conservative care with surgery if needed. Outcome measures were recovery and leg pain severity. Recovery was registered on a 7-point Likert scale. Complete/near complete recovery was considered a satisfactory outcome. Leg pain severity was measured on a 0 - to $100-\mathrm{mm}$ visual analog scale. Multiple MRI characteristics of the degenerated disc herniation were independently scored by 3 spine experts. Cox models were used to study the influence of MRI variables on rate of recovery, and linear mixed models were used to determine the predictive value of MRI variables for leg pain severity during follow-up. The interaction of each MRI predictor with treatment allocation was tested. There were no study-specific conflicts of interest.

RESULTS Baseline MRI variables associated with less leg pain severity were the reader's assessment of presence of nerve root compression $(p<0.001)$, and assessment of extrusion compared with protrusion of the disc herniation $(p=$ 0.006). Both variables tended to be associated, but not significantly, with satisfactory outcome during follow-up (HR 1.45 , $95 \% \mathrm{Cl} 0.93-2.24$, and $\mathrm{HR} 1.24,95 \% \mathrm{Cl} 0.96-1.61$, respectively). The size of disc herniation at baseline was not associated with outcome. There was no significant change in the effects between treatment groups.

CONCLUSIONS MRI assessment of the presence of nerve root compression and extrusion of a herniated disc at baseline was associated with less leg pain during 1-year follow-up, irrespective of a surgical or conservative treatment. MRI findings seem not to be helpful in determining which patients might fare better with early surgery compared with a strategy of prolonged conservative care.

Clinical trial registration no.: ISRCTN26872154 (controlled-trials.com)

http://thejns.org/doi/abs/10.3171/2015.10.SPINE15858

KEY WORDS sciatica; MRI; prognosis; effect modification; disc herniation; nerve root compression; degenerative

$\mathrm{S}$ CIATICA, also called sciatic neuralgia or lumbosacral radicular syndrome, is the most common neurological spine disease. It is usually caused by frequently occurring degenerative disc disease, resulting in compression or irritation of a nerve root by herniating disc material. The estimated annual prevalence rate is reported to be between $2.2 \%$ and $34 \% .{ }^{20}$ Differences in study populations and definitions of sciatic symptoms explain most of the variation of reported prevalence estimates. The natural history of sciatica is favorable, with spontaneous resolution of the leg pain within 8 weeks in $60 \%-80 \%$ of patients experiencing their first episode of sciatica. ${ }^{19,33} \mathrm{~Pa}-$

ABBREVIATIONS RCT = randomized controlled trial; RDQ = Roland Disability Questionnaire; VAS = visual analog scale. SUBMITTED July 22, 2015. ACCEPTED October 6, 2015. INCLUDE WHEN CITING Published online February 12, 2016; DOI: 10.3171/2015.10.SPINE15858.

* Drs. el Barzouhi and Verwoerd contributed equally to this work. 
tients with severe symptoms who fail to respond to conservative care for at least 6-8 weeks have an indication for MRI. ${ }^{19}$ However, despite the guidelines, many patients in Western society seem to receive earlier MRI, often without any indication for surgery.

When severe symptoms persist, surgery as a treatment modality is considered. MRI is used to assess whether a herniated disc with nerve root compression is indeed present, and what surgical approach is the most optimal. For instance, surgery for a mediolateral sequestrated herniated disc at L4-5 needs a completely different method than an intraforaminally located contained herniated disc at L5$\mathrm{S} 1$, even though both disc herniations give rise to a neurologically identical nerve root syndrome of L-5. Patients for whom conservative care fails and in whom clinical findings correspond well to imaging findings may qualify for surgery. Despite this common algorithm, surgical treatment rates for lumbar discectomy vary widely among countries and even within countries., ${ }^{3,19}$ This may (in part) be due to lack of a clear definition of sciatica, a paucity of evidence on the value of diagnostic and therapeutic interventions, and a lack of clear clinical guidelines. ${ }^{19}$

Earlier, our group reported the results of a randomized controlled trial (RCT) designed to define optimal timing of surgery for patients with sciatica. ${ }^{31}$ The trial showed that patients recover twice as fast after early surgery compared with a strategy of prolonged conservative care. Furthermore, $39 \%$ of patients in the conservative group were still operated on within the 1-year follow-up. Despite the apparent benefit of surgery, effectiveness analysis found no differences in the final outcome after 1 year, thereby supporting a conservative approach, with surgery only if needed. ${ }^{31}$ However, because the success of this approach may differ between subgroups of patients, it is important to identify individuals who may benefit more from either early surgery or a strategy of prolonged conservative care. Our group also evaluated whether MRI at baseline could have predicted surgery in patients assigned to the conservative group of the trial. We concluded that MRI at baseline was unable to distinguish between patients who did and those who did not undergo delayed surgery. ${ }^{11}$ In another study, we evaluated the influence of clinical determinants on the rate of recovery in all patients included in the RCT. We found female sex, a positive Bragard sign, and the crossed straight leg raise test to be predictive of an unsatisfactory outcome. ${ }^{29}$

The present study aimed to assess: 1) the predictive value of various MRI variables for satisfactory outcome during 1-year follow-up, and 2) whether MRI facilitates decision making between early surgery and prolonged conservative care in patients with herniated disc-related sciatica.

\section{Methods \\ Study Population}

Patients for this study were participants in the Sciatica Trial, a multicenter RCT in patients with herniated discrelated sciatica persisting for $6-12$ weeks..$^{30,31}$ This study was registered with the ISRCTN registry (controlled-trials. com), and its registration no. is ISRCTN26872154. Patients were between the ages of 18 and 65 years and were included only if they had a dermatomal pattern of pain distribution with concomitant neurological disturbances that correlated to the same nerve root being affected as shown on MRI.

Patients for this study had sciatic symptoms so severe that they were eligible for surgery according to their family practitioners; patients were therefore referred to a neurologist. The attending neurologist subsequently evaluated whether these patients were eligible to participate in the Sciatica Trial. Patients were excluded if they presented with cauda equina syndrome, insufficient strength to move against gravity, identical complaints in the previous 12 months, prior spine surgery, pregnancy, severe coexisting disease, or if they were not between 18 and 65 years of age.

All participants who did not meet 1 or more of the aforementioned exclusion criteria underwent MRI. If the MRI showed a disc herniation with nerve root compression correlating with clinical symptoms according to the attending neurologist and neurosurgeon, the corresponding patient was eligible to participate in the RCT. A strategy of early surgery was compared with a strategy of prolonged conservative care for an additional 6 months followed by surgery for patients who did not improve or who needed surgery earlier because of aggravating symptoms. ${ }^{30,31}$ The medical ethics committees at the 9 participating hospitals approved the protocol. Written informed consent was obtained from all patients.

\section{MRI Protocol and Image Evaluation}

MRI scans were performed at all 9 participating hospitals using standardized protocols tailored to a 1.5-T scanner. Sagittal T1-weighted and transversal T1-weighted spin echo images of the lumbar spine were acquired. In addition, T2-weighted sagittal and axial series and contrast-enhanced (gadolinium) T1-weighted fat-suppressed images were obtained. Two experienced neuroradiologists (B.K. and G.L.) and 1 neurosurgeon (C.V.) independently evaluated all MR images. The readers were not provided any clinical information and were not involved in the selection or care of the included patients.

To standardize the nomenclature, each reader was given a manual containing definitions of imaging characteristics based on recommendations from the combined task forces of the North American Spine Society, the American Society of Spine Radiology, and the American Society of Neuroradiology for classification of lumbar disc pathology. ${ }^{13}$ Vertebral endplate signal changes were defined according to the criteria of Modic et al. ${ }^{23,25}$ Before the start of the study, the readers met in person to evaluate and refine the standardized definitions.

After reaching final consensus, standardized case record forms with these final definitions were used to evaluate the images (Table S1). The presence of nerve root compression and clinically relevant characteristics of the disc level and disc herniation (e.g., size, location, and morphology) were scored for the disc level with the most severe nerve root compression. Based on the literature and clinical practice, we selected 9 MRI variables from this standardized case record form as the most relevant to test for their association with clinical outcome during the 1-year follow-up. 
For assessment of the presence of nerve root compression on MRI at baseline, a 4-point scale was used: 1) "Definite about the presence;" 2) "Probable about the presence" if there was some doubt but the probability was $\geq 50 \%$; 3 ) "Possible about the presence" if there was reason to consider but the probability was $<50 \%$; and 4 ) "Definite about the absence." The first 2 categories were combined and categorized as "Assessed as having nerve root compression" and the last 2 categories were combined and categorized as "Assessed as not having nerve root compression."

\section{Outcome Measures}

Outcome measures included: 1) a 7-point Likert selfrating scale of global perceived recovery, based on the question of how the patient experienced recovery compared with baseline (answers ranged from "Completely recovered" to "Much worse");1 2) the Roland Disability Questionnaire (RDQ) for sciatica (scores ranged from 0 to 23, with higher scores indicating worse functional status); $; 2$ and 3) the 0 - to $100-\mathrm{mm}$ visual analog scale (VAS) for leg and back pain (with 0 representing no pain, and 100 representing the worst pain ever experienced). ${ }^{6}$ These outcome measures were assessed at baseline and at 2, 4, 8, $12,26,38$, and 52 weeks.

\section{Statistical Analysis}

The majority opinion of the 3 readers regarding the MRI characteristics (i.e., the answer independently given by a minimum of 2 of 3 readers) was used in the analysis. Details on the interobserver agreement for the MRI findings were published earlier. ${ }^{12}$

Perceived recovery was defined as "Complete" or "Nearly complete disappearance of symptoms" on the patient-reported 7-point Likert scale for global perceived recovery, whereas a score in the remaining 5 categories was marked as a poor or unsatisfactory outcome and defined as "No recovery." 30,31 Cox proportional hazards models were used to study the relationship between MRI variables and time until perceived recovery (as determined by the prescheduled points of outcome registration during follow-up).

Multivariate linear mixed-effects models were used to study the relationship between MRI variables and leg pain severity during follow-up. In both the Cox proportional hazards models and the linear mixed regression models, all univariate relationships between MRI variables and outcome were also adjusted for the randomization arm. Additionally, when an MRI variable proved to significantly predict perceived recovery or leg pain severity during follow-up, differences in RDQ score and VAS back pain score determined at 1 year between the subcategories of this variable were assessed using a Student t-test.

Effect modification of each MRI predictor was tested in the Cox proportional hazards models and the linear mixed regression models containing the treatment allocation, the MRI predictor, and the interaction between them. We prespecified that when a predictor showed a significant interaction, we would enter this predictor in a repeated measurements analysis for the RDQ for sciatica and the VAS for back pain, to test whether the interaction also held in linear mixed regression models. Statistical significance was defined as a $\mathrm{p}$ value $<0.05$.

\section{Results}

A total of 599 patients were screened, of whom 204 were excluded (180 patients met exclusion criteria and 24 refused to participate). ${ }^{31}$ The 395 patients who remained underwent MRI. Of these 395 patients, 112 patients were excluded (70 patients had no disc herniation on MRI, 31 recovered, and 11 refused to participate in the study), leaving 283 patients eligible to participate in the study. No significant baseline differences were found between the $141 \mathrm{pa}-$ tients randomized to early surgery and the 142 patients randomized to prolonged conservative care (Table 1). Of the patients assigned to early surgery, $10 \%$ were assessed not to have nerve root compression on MRI at baseline, compared with $8 \%$ of the patients assigned to receive prolonged conservative care. In both treatment groups, 3 (2.1\%) patients had a bulging disc instead of disc herniation.

Of the 141 patients assigned to receive early surgical treatment, 16 recovered before surgery could be performed. Of the 142 patients assigned to prolonged conservative care, $55(39 \%)$ underwent surgery during the first year. In the early surgery group, $3.2 \%$ of patients had recurrent sciatica leading to a second surgical intervention, compared with $1.8 \%$ of patients in the conservative treatment group who underwent surgery. Complications occurred in $1.6 \%$ of all surgical patients, consisting of 2 dural tears and 1 wound hematoma. All complications resolved spontaneously. At 1-year follow-up, patients reported a mean score of 10.8 on the VAS for leg pain (mean score of 11.0 for patients in the early surgery group, and 10.6 for patients in the conservative treatment group) and $84 \%$ of the patients reported that they were recovered (86\% in the early surgery group and $83 \%$ in the prolonged conservative care group).

\section{Rate of Recovery According to Baseline MRI Characteristics}

Patients assessed to have nerve root compression on baseline MRI tended to have a higher, but nonsignificant, rate of recovery compared with patients in whom no nerve root compression was assessed on MRI (HR adjusted for treatment allocation 1.45, 95\% CI 0.93-2.24). However, only $9 \%$ of the included patients were not assessed as having nerve root compression on MRI. Table 2 shows the rate of recovery according to characteristics of the affected disc level or herniated disc on baseline MRI. Patients who were assessed with an extrusion as the herniation form tended to have a higher, but nonsignificant, rate of recovery compared with patients with a protrusion as the herniation form (HR 1.24, 95\% CI 0.96-1.61).

Patients assessed at baseline as having a large herniated disc ( $\geq 50 \%$ in relation to the spinal canal) did not report a significantly higher rate of recovery compared with patients with a smaller disc herniation (HR 1.09,95\% CI 0.80-1.48). Table S2 shows the distribution of different sizes of the disc herniation in relation to the spinal canal $(<25 \%, 25 \%-50 \%, 51 \%-75 \%$, and $>75 \%)$ for the randomization groups, the patients who crossed over to surgery, 
TABLE 1. Baseline characteristics of the study population of 283 patients with sciatica*

\begin{tabular}{|c|c|c|}
\hline \multirow[b]{2}{*}{ Characteristic } & \multicolumn{2}{|c|}{ Study Group } \\
\hline & Early Surgery, $n=141$ & $\begin{array}{l}\text { Prolonged Conservative } \\
\text { Treatment, } n=142\end{array}$ \\
\hline Age in yrs & $41.7 \pm 10.0$ & $43.4 \pm 9.6$ \\
\hline Sex, M & $89(63)$ & $97(68)$ \\
\hline Body mass index $†$ & $25.9 \pm 4.1$ & $25.5 \pm 3.3$ \\
\hline Duration of sciatica in wks & $9.4 \pm 2.4$ & $9.5 \pm 2.2$ \\
\hline Smoker & $57(40)$ & $52(37)$ \\
\hline \multicolumn{3}{|l|}{ Suspected disc level \& type of displacement on MRI } \\
\hline L3-4 herniation & $6(4)$ & $4(3)$ \\
\hline L4-5 herniation & $63(45)$ & $51(36)$ \\
\hline L4-5 bulging & $2(1)$ & $1(1)$ \\
\hline L5-S1 herniation & $69(49)$ & $84(59)$ \\
\hline L5-S1 bulging & $1(1)$ & $2(1)$ \\
\hline \multicolumn{3}{|l|}{ MRI-assessed nerve root compression } \\
\hline Definite: no doubt about the presence of nerve root compression & $90(64)$ & $102(72)$ \\
\hline Probable: some doubt but probability $\geq 50 \%$ & $37(26)$ & $29(20)$ \\
\hline Possible: reason to consider but probability $<50 \%$ & $11(8)$ & $10(7)$ \\
\hline Definitely no root compression & $3(2)$ & $1(1)$ \\
\hline Sensory loss & $92(65)$ & $105(74)$ \\
\hline Abnormal reflexes $\ddagger$ & $89(63)$ & $101(71)$ \\
\hline Muscle weakness§ & $103(73)$ & $115(81)$ \\
\hline Abnormal neurological test results $\llbracket$ & $131(93)$ & $129(91)$ \\
\hline RDQ score** & $16.5 \pm 4.4$ & $16.1 \pm 3.9$ \\
\hline VAS leg pain score, mm†† & $67.3 \pm 19.6$ & $64.4 \pm 21.2$ \\
\hline VAS back pain score, mm†† & $34.0 \pm 29.6$ & $30.8 \pm 27.7$ \\
\hline \multicolumn{3}{|c|}{$\begin{array}{l}\text { * Values are expressed as no. (\%) or the mean } \pm \text { SD. No significant baseline differences were observed in the intention-to-treat group. } \\
\text { †ody mass index is the weight in kilograms divided by the square of the height in meters. } \\
\text { f Reflexes were rated as abnormal if absent, less than the other side, or in cases of an extensor plantar response (Babinski sign). } \\
\S \text { Muscle strength was considered normal in cases of Medical Research Council Grade } 5 \text {, whereas Medical Research Council Grade } 4 \text { or less } \\
\text { was rated abnormal. } \\
\text { T Six neurological tests were performed (Lasègue sign, crossed straight leg raising, Kemp sign, Bragard sign, walking on heels, and walking on } \\
\text { toes). One or more non-normal test result was considered to be an abnormal result. } \\
\text { ** The RDQ for sciatica is a disease-specific disability scale that measures the functional status of patients with pain in the leg or back. Scores } \\
\text { range from } 0 \text { to } 23 \text {, with higher scores indicating worse functional status. } \\
+\dagger \text { The intensity of pain is indicated on a horizontal } 100-\mathrm{mm} \text { VAS, with } 0 \text { representing no pain and } 100 \text { representing the worst pain ever } \\
\text { experienced. }\end{array}$} \\
\hline
\end{tabular}

and the actual treatment group. No remarkable differences in distribution were seen. For all MRI variables investigated, $\mathrm{p}$ values for group interaction were nonsignificant (all $\mathrm{p}$ values for interaction $>0.26$ ).

\section{Leg Pain Severity According to Baseline MRI Characteristics}

Table 3 presents leg pain severity according to baseline MRI characteristics. Patients assessed to have nerve root compression on baseline MRI reported significantly less leg pain severity during follow-up compared with patients who had no nerve root compression on baseline MRI (estimate of reduction of VAS leg pain score of $11.69,95 \%$ CI 5.87-17.50). Similarly, patients assessed to have nerve root compression on baseline MRI also reported a more favorable RDQ score (3.0 vs 7.4, $\mathrm{p}=0.01)$ and a lower VAS back pain score (13.8 vs $29.7, \mathrm{p}=0.02)$ at 1 -year follow-up.
Patients with extrusions at baseline reported less leg pain compared with patients with protrusions (estimate of reduction of VAS leg pain score of 4.98, 95\% CI 1.42-8.54). Patients assessed with extrusions as the herniation form on baseline MRI did not report a significantly more favorable RDQ score at 1-year follow-up ( 2.9 vs $4.3, \mathrm{p}=0.07$ ); however, patients with extrusions reported a lower VAS back pain score at 1-year follow-up (12.9 vs 20.2, $\mathrm{p}=0.02$ ). Other characteristics of the affected disc level or herniated disc on baseline MRI showed no relationship with leg pain severity. For all MRI variables investigated, none showed an interaction with treatment allocation (all $\mathrm{p}$ values for interaction $>0.22$ ).

In a subanalysis involving only patients who were randomized to conservative care, we compared the disc herniation size between those who crossed over to surgery $(n=55)$ and those who did not $(n=87)$. Large disc her- 
TABLE 2. Association between baseline MRI findings and rate of recovery during the first year after randomization*

\begin{tabular}{|c|c|c|c|c|c|}
\hline Variable & Comparison (\%) & $\begin{array}{l}\text { Subgroup Effect } \\
\text { HR }(95 \% \mathrm{Cl})\end{array}$ & $\begin{array}{l}\text { Subgroup Effect HR } \\
\text { Adjusted for Treatment } \\
\text { Allocation }(95 \% \mathrm{Cl}) \dagger\end{array}$ & $\begin{array}{l}\text { p Value of } \\
\text { Adjusted } \\
\text { HR }\end{array}$ & $\begin{array}{l}p \text { Value } \\
\text { of Group } \\
\text { Interactionf }\end{array}$ \\
\hline Presence of nerve root compression & Yes (91) vs no (9) & 1.34 (0.87 to 2.08$)$ & 1.45 (0.93 to 2.24$)$ & 0.10 & 0.92 \\
\hline Level of disc herniation & L5-S1 (55) vs L3-4 or L4-5 (45) & $0.96(0.75$ to 1.22$)$ & $1.02(0.80$ to 1.31$)$ & 0.88 & 0.87 \\
\hline Size of disc herniation & $\begin{array}{l}\geq 50 \%(21) \text { vs }<50 \%(79) \text { in relation to } \\
\quad \text { spinal canal }\end{array}$ & 1.02 (0.75 to 1.38$)$ & 1.09 (0.80 to 1.48$)$ & 0.60 & 0.37 \\
\hline Location of disc herniation & $\begin{array}{l}\text { Central and/or subarticular (91) vs } \\
\text { foraminal \&/or extraforaminal (9) }\end{array}$ & 1.07 (0.70 to 1.64$)$ & 1.08 (0.71 to 1.66$)$ & 0.72 & 0.68 \\
\hline Morphology of disc herniation & Extrusion (64) vs protrusion (36) & 1.15 (0.89 to 1.49$)$ & $1.24(0.96$ to 1.61$)$ & 0.10 & 0.26 \\
\hline $\begin{array}{l}\text { Absence of epidural fat adjacent to } \\
\text { dural sac or surrounding nerve root } \\
\text { sheath }\end{array}$ & $\begin{array}{l}\text { Completely (60) vs partly or not } \\
\text { disappeared (40) }\end{array}$ & 1.01 (0.79 to 1.30$)$ & 1.08 (0.84 to 1.39$)$ & 0.54 & 0.95 \\
\hline $\begin{array}{l}\text { Presence of impaired discs on other } \\
\text { disc levels }\end{array}$ & Yes (79) vs no (21) & $1.13(0.83$ to 1.53$)$ & 1.08 (0.80 to 1.47$)$ & 0.61 & 0.54 \\
\hline $\begin{array}{l}\text { Presence of vertebral endplate signal } \\
\text { changes at level of herniated disc }\end{array}$ & Present (33) vs absent (67) & 1.15 (0.89 to 1.51$)$ & $1.12(0.86$ to 1.46$)$ & 0.42 & 0.51 \\
\hline $\begin{array}{l}\text { Presence of Schmorl nodules (her- } \\
\text { niation of disc into vertebral body } \\
\text { endplate) at level of herniated disc }\end{array}$ & Present (5) vs absent (95) & 1.24 (0.71 to 2.17$)$ & 1.34 (0.77 to 2.35$)$ & 0.31 & 0.55 \\
\hline
\end{tabular}

niations ( $\geq 50 \%$ of the spinal canal) were nearly equally distributed between those who did and those who did not undergo surgery $(24 \%$ vs $21 \%, \mathrm{p}=0.65)$.

\section{Discussion \\ Main Results}

In this patient group, the size of disc herniation at baseline did not influence outcome during the 1-year followup. However, patients with nerve root compression seen on baseline MRI reported less leg pain during follow-up compared with patients with no nerve root compression depicted on MRI, irrespective of surgical or conservative treatment. In accordance with clinical observations, patients without a clear compressive etiology of their severe sciatic symptoms experienced more persistent leg pain. Apparently, a noncompressive etiology of sciatica is more difficult to resolve. Patients assessed with an extrusion reported less leg pain during follow-up compared with patients with a protrusion; again, this finding was irrespective of surgical or conservative treatment. Furthermore, no interaction was found between assigned treatment and baseline MRI findings for recovery or persisting leg pain. This indicates that, although some baseline MRI findings were informative in predicting leg pain severity during the first year after diagnosis, they are unable to predict which patients may benefit from early surgery versus prolonged conservative care.

\section{Comparison With Literature}

Earlier studies examined the prognostic value of various MRI characteristics. ${ }^{32}$ However, difficulties may arise when correlating MRI findings with prognosis, because the treatment choice following the MRI findings may reflect patient prognosis, and the preferences of both the practice community and the physician. From a clinical viewpoint, we expected a larger-size disc herniation at baseline to be associated with a better outcome in the surgically treated cohort during follow-up than in the conservatively treated patients. However, the presence of large disc herniations (present in $21 \%$ of our included patients) showed no prognostic value, irrespective of surgical or prolonged conservative treatment. This is in concordance with a study in surgically treated patients and another in nonsurgically treated patients, both of which showed no correlation between size of the disc herniation and outcome. ${ }^{16,26}$ In contrast, another retrospective cohort study showed that patients with a thecal sac compression of one-third or more had a greater surgical treatment effect than those with small disc herniations, although for conservatively treated patients no differences in outcome were seen. ${ }^{22}$

Overall, differences in the prognostic value of MRI characteristics between studies may be largely explained by differences in study design, study population, sample size, and the treatment received. The discrepancy between studies regarding disc herniation size may be due to the interpretation of small and large disc herniations; this largely depends on the reviewer and how disc herniation size is measured. The method in which the size is correlated to the width of the canal seems to be the most reliable; however, the level at which the size of the canal is determined has considerable influence on the measurement of the size of the bulging disc. Moreover, it is debatable whether the size of the bony canal should be measured, or the size of the canal minus the flavum ligament. Morphometric studies would benefit from clear guidelines on this topic. 
TABLE 3. Repeated measures analysis of baseline MRI findings for less severe leg pain during 1-year follow-up

\begin{tabular}{|c|c|c|c|c|c|}
\hline Variable & Comparison (\%) & Estimate $(95 \% \mathrm{Cl})$ & $\begin{array}{l}\text { Estimate Adjusted for } \\
\text { Treatment Allocation } \\
\qquad(95 \% \mathrm{Cl})^{*}\end{array}$ & $\begin{array}{l}p \text { Value of } \\
\text { Adjusted } \\
\text { Estimate }\end{array}$ & $\begin{array}{l}\text { p Value } \\
\text { of Group } \\
\text { Interaction† }\end{array}$ \\
\hline Presence of nerve root compression & Yes (91) vs no (9) & 11.11 (5.04 to 17.18$)$ & 11.69 (5.87 to 17.50$)$ & $<0.001$ & 0.58 \\
\hline Level of disc herniation & $\begin{array}{l}\text { L5-S1 (55) vs L3-4 or } \\
\text { L4-5 (45) }\end{array}$ & $1.26(-2.29$ to 4.81$)$ & $2.21(-1.21$ to 5.64$)$ & 0.21 & 0.60 \\
\hline Size of disc herniation & $\begin{array}{l}\geq 50 \%(21) \text { vs }<50 \%(79) \text { in } \\
\quad \text { relation to spinal canal }\end{array}$ & $0.38(-4.06$ to 4.82$)$ & $0.82(-3.46$ to 5.11$)$ & 0.71 & 0.86 \\
\hline Location of disc herniation & $\begin{array}{l}\text { Central and/or subarticular } \\
\text { (91) vs foraminal \&/or } \\
\text { extraforaminal (9) }\end{array}$ & $3.66(-2.55$ to 9.87$)$ & $3.51(-2.48$ to 9.49$)$ & 0.25 & 0.70 \\
\hline Morphology of disc herniation & $\begin{array}{l}\text { Extrusion (64) vs protru- } \\
\quad \text { sion (36) }\end{array}$ & $4.57(0.89$ to 8.25$)$ & 4.98 (1.42 to 8.54$)$ & 0.006 & 0.24 \\
\hline $\begin{array}{l}\text { Absence of epidural fat adjacent to dural sac or } \\
\text { surrounding nerve root sheath }\end{array}$ & $\begin{array}{l}\text { Completely (59) vs partly } \\
\text { or not disappeared (41) }\end{array}$ & $1.81(-1.77$ to 5.39$)$ & $2.74(-0.74$ to 6.21$)$ & 0.12 & 0.29 \\
\hline Presence of impaired discs on other disc levels & Yes (79) vs no (21) & $1.36(-2.99$ to 5.71$)$ & $1.04(-3.18$ to 5.25$)$ & 0.99 & 0.41 \\
\hline $\begin{array}{l}\text { Presence of vertebral endplate signal changes } \\
\text { at level of herniated disc }\end{array}$ & $\begin{array}{l}\text { Present (33) vs absent } \\
\quad(67)\end{array}$ & $-0.92(-4.66$ to 2.82$)$ & $-0.07(-3.69$ to 3.55$)$ & 0.97 & 0.96 \\
\hline $\begin{array}{l}\text { Presence of Schmorl nodules (herniation of } \\
\text { disc into vertebral body endplate) at level of } \\
\text { herniated disc }\end{array}$ & Present (5) vs absent (95) & $-0.15(-8.45$ to 8.15$)$ & $1.50(-6.52$ to 9.52$)$ & 0.71 & 0.22 \\
\hline
\end{tabular}

* Treatment strategies were randomized by allocation to early surgery versus prolonged conservative care.

$\dagger$ Tests whether the estimate of randomized allocation to early surgery versus prolonged conservative care differs between the subgroups analyzed.

Recent studies support the theory of a multifactorial etiologic origin of sciatica, in which spinal nerve irritation may result from both compressive and noncompressive causes. ${ }^{7,10}$ Therefore, as with other diseases, differences in etiology of sciatica may (theoretically) result in different outcomes. For example, a noncompressive (possibly inflammatory) cause of sciatica may be more difficult to resolve spontaneously. The present study in 283 patients with sciatica, as well as 2 earlier studies, supports this theory and found a better prognosis for patients with clear nerve root compression on MRI. ${ }^{16,34}$ However, 2 other studies found no significant association for nerve root compression. ${ }^{18,24}$ Another (retrospective) cohort study observed better surgical outcomes for patients with nerve root compression, whereas the outcomes in the nonsurgical groups were similar. ${ }^{22}$ Again, these differences in observed prognostic value of the presence of nerve root compression may be largely explained by differences in study design, study population, sample size, and treatment received.

Different classification methods for morphology of disc herniations are used, thereby complicating comparisons between studies. A recent systematic review, which evaluated the probability of spontaneous regression among different types of lumbar herniated discs, found a rate of spontaneous regression of $96 \%$ for disc sequestration, $70 \%$ for disc extrusion, and $41 \%$ for disc protrusion. ${ }^{4}$ The higher rate of spontaneous regression of disc extrusions compared with disc protrusions may indicate a better prognosis for extruded disc herniations in conservatively treated patients. In surgically treated patients, it is feasible that decompression of the nerve is more effective in cases of extrusions.

In the present study, the finding of a better prognosis for patients assessed with an extruded disc (present in 64\% of the included patients) tends to support these theories. Moreover, another study in conservatively treated patients, and 2 studies in surgically treated patients, also found better outcome results for patients with extrusions. ${ }^{8,15,18}$ However, another study (with a retrospective cohort, in which $61 \%$ of patients had disc surgery) observed no difference in outcomes between different disc morphology groups. ${ }^{22}$ Again, the way in which the disc extrusion or protrusion is determined has a strong influence on the outcome. However, until clear guidelines become available, no firm conclusions can be drawn. Moreover, it is noteworthy that the size of the herniated disc is not associated with outcome, whereas the presence of extrusion is; perhaps there is an association between size and extrusion.

For the presence of both nerve root compression and an extruded disc, clear and significant results were seen for their prognostic value on the outcome "leg pain intensity" during follow-up. However, results for the outcome "recovery" were not significant (although a tendency was found because both $\mathrm{p}$ values were 0.10 ). We do not have a clear explanation for this discrepancy between outcome measures.

The present study demonstrates that the MRI parameters studied are not helpful in the decision-making process of early surgery versus prolonged conservative care. Even for the MRI variables indicating possibly more benefit from surgery (i.e., large disc herniation and extruded disc), there was no interaction with treatment allocation. A similar study in the same patient population showed that only the history item on the presence of "sciatica provoked by sitting" showed interaction with the timing of surgery and thus influenced the rate of recovery. ${ }^{28}$ Thus, unfortu- 
nately, we conclude that clinical and MRI characteristics are minimally informative in determining which patients might fare better with early surgery compared with a strategy of prolonged conservative care.

It seems that the criteria threshold is lowering with regard to performing an MRI study in patients with low back pain. ${ }^{5}$ In addition, with improvements in the resolution of images, more and smaller abnormalities will probably be detected. These may be clinically irrelevant, ${ }^{9}$ but may create the potential for overestimation of the prevalence of surgically amenable diseases in the lumbar spine. ${ }^{21}$ Disc herniations on MRI are observed in $28 \%-76 \%$ of persons without any symptoms. ${ }^{2,17}$ The marked increase in rates of lumbar spine surgery has partly been linked to the increased availability of advanced diagnostic imaging techniques. ${ }^{9,21}$ Moreover, spine imaging may have an adverse effect; i.e., telling patients they have an imaging abnormality can lead to unintended harm related to disease labeling. ${ }^{14,35}$ The present study adds that, within this highly selected population of patients with herniated disc-related sciatica for 6-12 weeks, MRI has no value in the decision making between early surgery and prolonged conservative care. Patients with clear sciatic symptoms and a severe disc herniation with clear nerve root compression on MRI might still benefit from conservative care. Even those abnormalities seen on MRI that do match clinical symptoms may well resolve spontaneously.

\section{Study Limitations}

The main drawback of the present study was the selection of patients from neurological outpatient clinics after referral by primary care physicians; therefore, also due to the stringent inclusion criteria, there was less contrast among patients in terms of baseline MRI characteristics. Although the trial had a pragmatic study design, the patients were highly selected and had a monodermatomal pain problem leading to a clear-cut sciatica condition. However, in daily practice, for most patients the neurological syndrome is not as clear; thus, MR images may not show nerve root compression or very small herniated discs. In reality (i.e., outside RCTs), there is considerable contrast between groups of patients who are experiencing similar pain-patients with disc-related nerve root compression versus those without morphological nerve root problems. Although, hypothetically, in MRI studies this contrast would lead to a better MRI discrimination, this has not been proven. If the sciatica is not intense, or the MRI findings are not consistent with clear-cut nerve root compression, we advise withholding surgery.

Furthermore, the present results should be interpreted carefully. During planning of the clinical outcome study, the power analysis was based on how many patients would be required to detect a difference in clinical outcome between early surgery and prolonged conservative care for sciatica. No separate power analysis was performed for the present study. Also, because some MRI characteristics were present in only 5\%-9\% of patients, a larger study population would have been desirable. In addition, to minimize bias due to multiple testing, we did not control for age or other MRI findings in the analyses. This may have resulted in blurring of results.

\section{Conclusions}

The size of disc herniation assessed at baseline did not influence outcome during 1-year follow-up in patients with herniated disc-related sciatica. In this highly selected study population, baseline MRI findings were not helpful in determining which patients might fare better with early surgery compared with a strategy of prolonged conservative care. Only the assessed presence of nerve root compression and disc morphology (i.e., disc extrusion) on MRI may be informative to predict the patient's prognosis in sciatica, and might even lead to greater contrast in outcomes among a "regular" outpatient population. If the sciatica is not intense, or the MRI findings are not consistent with clear-cut nerve root compression, we advise withholding surgery.

\section{Acknowledgments}

The Sciatica Trial was supported by a grant from The Netherlands Organisation for Health Research and Development (ZonMW) and the Hoelen Foundation, The Hague.

\section{References}

1. Bombardier C: Outcome assessments in the evaluation of treatment of spinal disorders: summary and general recommendations. Spine (Phila Pa 1976) 25:3100-3103, 2000

2. Boos N, Rieder R, Schade V, Spratt KF, Semmer N, Aebi M: 1995 Volvo Award in clinical sciences. The diagnostic accuracy of magnetic resonance imaging, work perception, and psychosocial factors in identifying symptomatic disc herniations. Spine (Phila Pa 1976) 20:2613-2625, 1995

3. Cherkin DC, Deyo RA, Loeser JD, Bush T, Waddell G: An international comparison of back surgery rates. Spine (Phila Pa 1976) 19:1201-1206, 1994

4. Chiu CC, Chuang TY, Chang KH, Wu CH, Lin PW, Hsu WY: The probability of spontaneous regression of lumbar herniated disc: a systematic review. Clin Rehabil 29:184-195, 2015

5. Chou R, Qaseem A, Owens DK, Shekelle P: Diagnostic imaging for low back pain: advice for high-value health care from the American College of Physicians. Ann Intern Med 154:181-189, 2011

6. Collins SL, Moore RA, McQuay HJ: The visual analogue pain intensity scale: what is moderate pain in millimetres? Pain 72:95-97, 1997

7. Cuéllar JM, Borges PM, Cuéllar VG, Yoo A, Scuderi GJ, Yeomans DC: Cytokine expression in the epidural space: a model of noncompressive disc herniation-induced inflammation. Spine (Phila Pa 1976) 38:17-23, 2013

8. Dewing CB, Provencher MT, Riffenburgh RH, Kerr S, Manos RE: The outcomes of lumbar microdiscectomy in a young, active population: correlation by herniation type and level. Spine (Phila Pa 1976) 33:33-38, 2008

9. Deyo RA: Magnetic resonance imaging of the lumbar spine. Terrific test or tar baby? N Engl J Med 331:115-116, 1994

10. Di Martino A, Merlini L, Faldini C: Autoimmunity in intervertebral disc herniation: from bench to bedside. Expert Opin Ther Targets 17:1461-1470, 2013

11. el Barzouhi A, Vleggeert-Lankamp CL, Lycklama à Nijeholt GJ, Van der Kallen BF, van den Hout WB, Koes BW, et al: Predictive value of MRI in decision making for disc surgery for sciatica. J Neurosurg Spine 19:678-687, 2013

12. el Barzouhi A, Vleggeert-Lankamp CL, Lycklama à Nijeholt GJ, Van der Kallen BF, van den Hout WB, Verwoerd AJ, et al: Magnetic resonance imaging interpretation in patients with sciatica who are potential candidates for lumbar disc surgery. PLoS One 8:e68411, 2013 
13. Fardon DF, Milette PC: Nomenclature and classification of lumbar disc pathology. Recommendations of the Combined task Forces of the North American Spine Society, American Society of Spine Radiology, and American Society of Neuroradiology. Spine (Phila Pa 1976) 26:E93-E113, 2001

14. Fisher ES, Welch HG: Avoiding the unintended consequences of growth in medical care: how might more be worse? JAMA 281:446-453, 1999

15. Folman Y, Shabat S, Catz A, Gepstein R: Late results of surgery for herniated lumbar disk as related to duration of preoperative symptoms and type of herniation. Surg Neurol 70:398-402, 2008

16. Halldin K, Lind B, Rönnberg K, Göthlin J, Gadeholt-Göthlin $\mathrm{G}$, Zoëga B, et al: Three-dimensional radiological classification of lumbar disc herniation in relation to surgical outcome. Int Orthop 33:725-730, 2009

17. Jensen MC, Brant-Zawadzki MN, Obuchowski N, Modic MT, Malkasian D, Ross JS: Magnetic resonance imaging of the lumbar spine in people without back pain. N Engl J Med 331:69-73, 1994

18. Jensen TS, Albert HB, Sorensen JS, Manniche C, LeboeufYde C: Magnetic resonance imaging findings as predictors of clinical outcome in patients with sciatica receiving active conservative treatment. J Manipulative Physiol Ther 30:98-108, 2007

19. Koes BW, van Tulder MW, Peul WC: Diagnosis and treatment of sciatica. BMJ 334:1313-1317, 2007

20. Konstantinou K, Dunn KM: Sciatica: review of epidemiological studies and prevalence estimates. Spine (Phila Pa 1976) 33:2464-2472, 2008

21. Lurie JD, Birkmeyer NJ, Weinstein JN: Rates of advanced spinal imaging and spine surgery. Spine (Phila Pa 1976) 28:616-620, 2003

22. Lurie JD, Moses RA, Tosteson AN, Tosteson TD, Carragee EJ, Carrino JA, et al: Magnetic resonance imaging predictors of surgical outcome in patients with lumbar intervertebral disc herniation. Spine (Phila Pa 1976) 38:1216-1225, 2013

23. Modic MT, Masaryk TJ, Ross JS, Carter JR: Imaging of degenerative disk disease. Radiology 168:177-186, 1988

24. Modic MT, Obuchowski NA, Ross JS, Brant-Zawadzki MN, Grooff PN, Mazanec DJ, et al: Acute low back pain and radiculopathy: MR imaging findings and their prognostic role and effect on outcome. Radiology 237:597-604, 2005

25. Modic MT, Steinberg PM, Ross JS, Masaryk TJ, Carter JR: Degenerative disk disease: assessment of changes in vertebral body marrow with MR imaging. Radiology 166:193-199, 1988

26. Oland G, Hoff TG: Intraspinal cross-section areas measured on myelography-computed tomography. The relation to outcome in nonoperated lumbar disc herniation. Spine (Phila Pa 1976) 21:1985-1990, 1996

27. Patrick DL, Deyo RA, Atlas SJ, Singer DE, Chapin A, Keller RB: Assessing health-related quality of life in patients with sciatica. Spine (Phila Pa 1976) 20:1899-1909, 1995

28. Peul WC, Arts MP, Brand R, Koes BW: Timing of surgery for sciatica: subgroup analysis alongside a randomized trial. Eur Spine J 18:538-545, 2009

29. Peul WC, Brand R, Thomeer RT, Koes BW: Influence of gen- der and other prognostic factors on outcome of sciatica. Pain 138: 180-191, 2008

30. Peul WC, van Houwelingen HC, van den Hout WB, Brand R, Eekhof JA, Tans JT, et al: Prolonged conservative treatment or 'early' surgery in sciatica caused by a lumbar disc herniation: rationale and design of a randomized trial [ISRCT 26872154]. BMC Musculoskelet Disord 6:8, 2005

31. Peul WC, van Houwelingen HC, van den Hout WB, Brand R, Eekhof JA, Tans JT, et al: Surgery versus prolonged conservative treatment for sciatica. N Engl J Med 356:2245-2256, 2007

32. Verwoerd AJ, Luijsterburg PA, Lin CW, Jacobs WC, Koes BW, Verhagen AP: Systematic review of prognostic factors predicting outcome in non-surgically treated patients with sciatica. Eur J Pain 17:1126-1137, 2013

33. Vroomen PC, de Krom MC, Slofstra PD, Knottnerus JA: Conservative treatment of sciatica: a systematic review. J Spinal Disord 13:463-469, 2000

34. Vroomen PC, Wilmink JT, de Krom M: Prognostic value of MRI findings in sciatica. Neuroradiology 44:59-63, 2002

35. Webster BS, Bauer AZ, Choi Y, Cifuentes M, Pransky GS: Iatrogenic consequences of early magnetic resonance imaging in acute, work-related, disabling low back pain. Spine (Phila Pa 1976) 38:1939-1946, 2013

\section{Disclosures}

The authors report no conflict of interest concerning the materials or methods used in this study or the findings specified in this paper.

\section{Author Contributions}

Conception and design: Verwoerd, el Barzouhi, Peul, Verhagen, Koes, Vleggeert-Lankamp. Acquisition of data: el Barzouhi, Lycklama à Nijeholt, Van der Kallen, Vleggeert-Lankamp. Analysis and interpretation of data: Verwoerd, el Barzouhi. Drafting the article: Verwoerd, el Barzouhi. Critically revising the article: all authors. Reviewed submitted version of manuscript: all authors. Approved the final version of the manuscript on behalf of all authors: Verwoerd. Statistical analysis: Verwoerd, el Barzouhi, Verhagen. Administrative/technical/material support: Verwoerd, el Barzouhi. Study supervision: Peul, Koes, VleggeertLankamp.

\section{Supplemental Information Online-Only Content}

Supplemental material is available with the online version of the article.

Tables S1 and S2. http://thejns.org/doi/suppl/10.3171/2015.10. SPINE15858.

\section{Correspondence}

Annemieke J. H. Verwoerd, Department of General Practice, Erasmus MC University Medical Center Rotterdam, P.O. Box 2040, Rotterdam 3000 CA, The Netherlands. email: j.verwoerd@ erasmusmc.nl. 